\title{
sciendo ERGONOMIC DIAGNOSIS OF A COMPUTER WORKSTATION
}

doi:10.2478/mape-2018-0093

Date of submission of the article to the Editor: 05/2018 Date of acceptance of the article by the Editor: 07/2018
MAPE 2018, volume 1, issue 1, pp. 739-744

\author{
Dr Iwona Żabińska \\ Dr Artur Kuboszek \\ Silesian University of Technology, Poland
}

\section{Ing. Erika Sujova, PhD.}

Technical University in Zvolen, Slovak Republic

Doc. Ing. Jan Zitnansky, PhD.

Slovak University of Agriculture, Slovak Republic

\begin{abstract}
The article presents the results of research carried out as a part of a project aimed at integrated ergonomic diagnosis of the work environment in terms of improvement of technical and psychosocial conditions. The research carried out so far included small and medium-sized enterprises located in the Śląskie Voivodeship. The tests included blue-collar workers as well as administrative (white-collar) workers. Ergonomic diagnosis was carried out by direct observation of employees at the workplace using tools such as the Ergonomic Control Test CET II and the Dortmund list. This article presents the results of ergonomic analysis at a workstation with a computer.
\end{abstract}

Keywords: ergonomics, ergonomic diagnosis, workplace, work on a computer.

\section{INTRODUCTION}

Ergonomics is a very broad concept, which is why there is no one universal definition of this field of science. The definition included in the Statute of the Polish Ergonomic Society of 1983 (Chapter II, Section 11) says that it is applied science, aimed at the optimal adaptation of tools, machines, devices, technologies, organization and material working environment, and general-use items to the physiological, psychological and social requirements and needs of a human. The analysis of this and other definitions leads to the conclusion that it is an applied science characterized by man-centered and its harmonious interaction with technical means. According to this principle, all activities related to the design of new and modifying existing technical measures should take place on the assumption that human well-being must be prioritized in relation to technical or economic criteria. Implementation of activities to ensure ergonomic working conditions can be done by introducing ergonomic principles at the moment of designing systems. Then it is called conceptual ergonomics. Wider use of corrective ergonomics is based on the correction of working conditions by modernization of existing and already working machines and devices and introduction of elements protecting people from adverse influences of the work environment. The problem of ergonomics at the workplace has one more, very important dimension. Activities of scientific communities that raise ergonomic problems at workplaces (Koszembar-Wiklik et al., 2015; Bartnicka, 2015, Bartnicka et al., 2017; Bartnicka at al., 2018; Mleczko, 2016; Winnicka-Jasłowska, et al., 2017) unfortunately does not bring the assumed effects. Employees' awareness of the principles of ergonomic work is, unfortunately, negligible, and the willingness to provide appropriate conditions for the ergonomic work of employees by business owners is also small. There is still a lot to do in this area. 
The article presents the results of research carried out as part of a project aimed at integrated ergonomic diagnosis of the work environment in terms of improving technical and psychosocial conditions. The results of an ergonomic diagnosis covering a number of sitting workstations with a computer are presented.

\section{METHODOLOGY OF RESEARCH}

The ergonomic diagnosis was carried out by direct observation of the employee while performing the tasks. The observation was supported by several research tools that allow for a relatively quick and accurate assessment of the ergonomic situation in the analyzed work environment. Due to the short time in which observations could be made in relation to a single workstation and the necessity to choose a universal tool for all groups and positions, it was decided to use the check list method - the Dortmund List (ESAC - Ergonomics System Analysis Check-list). This method was developed for the purpose of ergonomic diagnosis by B.C.E. Burger and accepted at the Second Ergonomic Congress in Dortmund in 1964. The advantage of the method is that it contains a set of questions through which a systematic analysis of various factors of the work components and related employee reactions to the workload, as well as environmental conditions and equipment of the workplace can be performed. The questions were divided into two groups: 138 general questions also called the main questions (questions of type A) and 188 specific questions (questions of type B). The latter are answered when it results from the answers to questions of type A. In addition, an indepth interview with employees was carried out using the workplace questionnaire form created for this purpose, containing questions being an extension of questions from the general CET2 list (Burger and Boer, 1968). This questionnaire helped to identify the ergonomic problems of the workplace from the point of view of the employee, it also allowed to determine the employees' awareness of the ergonomic requirements of the workplace. Additionally, 3DSSPP software was used to analyze the physical load of the musculoskeletal system for selected positions during the work performance. The human posture during work was modeled on the basis of photo documentation taken at work stations.

\section{CHARACTERISTIC OF A COMPUTER WORKSTATION.}

Correct working conditions at a computer station are related to ensuring compliance with the recommendations in four aspects. It is important to ensure:

- Proper work equipment

- Proper spatial organization of a computer workstation

- Proper position during work performance

- Proper work environment of human work

According to the presented recommendations (Kamińska and Tokarski, 2016), the properly equipped stand includes a desk with desktop dimensions at least $100 \times 80 \mathrm{~cm}$ and, what is important, with the height adjustment of the desktop. The office chair should be equipped with seat height adjustment (usually in the range from 40 to $50 \mathrm{~cm}$ ) and armrests also with height adjustment. If the height of the desk cannot be adjusted, it may be necessary to use the footrest. The computer monitor should be chosen according to the size of characters on the screen. It should provide adequate readability and sharpness of the image characterized by basic parameters such as: contrast above 1000:1 and brightness min. $250 \mathrm{~cd} / \mathrm{m}^{2}$. The keyboard and computer mouse should be selected for a particular user, taking into account the size of the hands.

The proper equipment of the computer station directly relates with ensuring proper organization of the workplace. Of course, this aspect is also influenced by the physical characteristics of the employee. The spatial organization of the workplace will depend on the height, weight and length of the worker's limbs. The most important principles to be followed when adjusting the computer station are (Kamińska and Tokarski, 2016): 
- the height of the chair and the height of the desk should be adjusted so that the keyboard is located at the height of the elbow (with the arms freely lowering downwards),

- the chair's adjustment should be chosen so that it is possible to take the angle in the knees and the angle in the hips - around $90^{\circ}-110^{\circ}$. The back of the chair should be placed so that it touches the blades and adheres to the lumbar spine,

- the screen should be located approx. $60 \mathrm{~cm}$ from the eyes. The monitor should be positioned in front of the worker so that the top edge is just below the eye level,

- the keyboard should positioned so that it allows the wrists to rest on gel pads and the forearms on the desk or armrests.

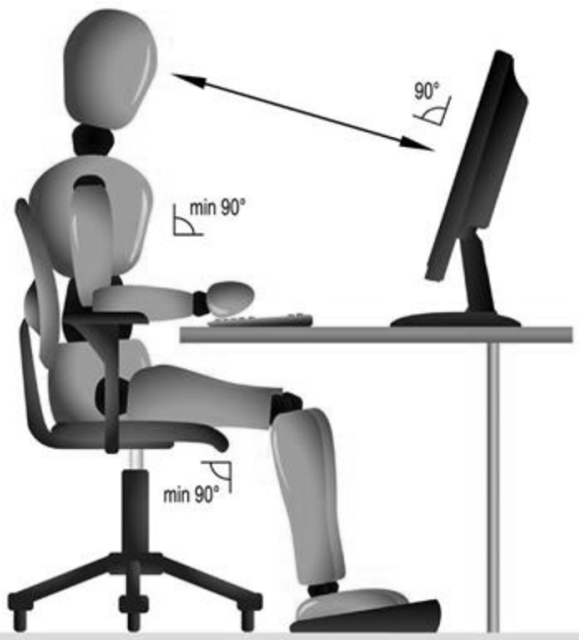

Fig. 1. Correct posture at work at a computer station.

Source: (Kamińska and Tokarski, 2016).

It is also important to ensure proper working environment conditions. The room should have access to natural light, with the possibility of its adjustment. The monitor should be placed sideways to the window to ensure good visual work conditions - without reflections and excessive contrasts. If the monitor cannot be set in this way, appropriate measures should be taken to limit the entry of sunlight into the room (blinds) and ensure the correct level of artificial light.

\section{ERGONOMIC DIAGNOSIS ON THE COMPUTER WORKSTATION.}

The research carried out so far included 8 enterprises in which about 120 employees were tested. In this group, 44 employees had a sitting position using a computer station. They were people working on computer workplaces continuously (for $100 \%$ of their working time) as well as people who also performed other work as part of their duties. However, it should be noted that even in the case of the second group, the time spent working at a desk using a computer was not less than $70-80 \%$ of working time. Observations carried out during the tests revealed a number of repeated irregularities resulting mainly from incorrect equipment of work stations:

\subsection{No height adjustment of the working surface of desks (tables)}

In the case of the tested stations, in no case was there any table that would allow adjustment of the surface height of the desktop. In two cases, the desktop turned out to be too low, while in $28(64 \%)$ it was too high. This problem seems to be the genesis of most other irregularities found in the organization of the workspace. In these 28 cases employees adjusted the height of office chairs to the convenience of legs, which in the absence of the possibility of lowering the tabletop level meant that the surfaces on which the computer keyboard was located were too high. 


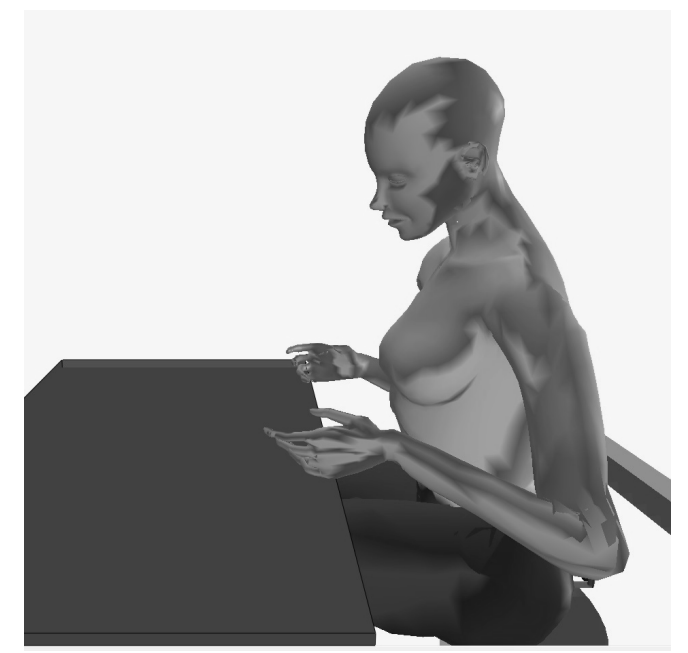

Fig. 2. Incorrect, too high position of the table top surface

\subsection{No adjustment of the height of the armrests.}

The research carried out showed that in $33(75 \%)$ cases office armchairs did not have armrests allowing height adjustment, while in 5 cases they did not have any armrests at all. At the same time, in these 33 cases, the armrests were found to be too low and did not fulfill their role of supporting the elbows and forearms in the right position.

\subsection{Setting the keyboard too far from the egde of the desk.}

The problem of too low armrests in most cases is a consequence of the unadjusted table height. Too high table does not allow to lean the forearms on the armrests and forces to take the position in which the elbows, forearms and hands are all based on the table top. In the consequence it forces the keyboard to be moved away from the recommended position ( 10 $\mathrm{cm}$ from the edge of the table) and to move it nearer the monitor.

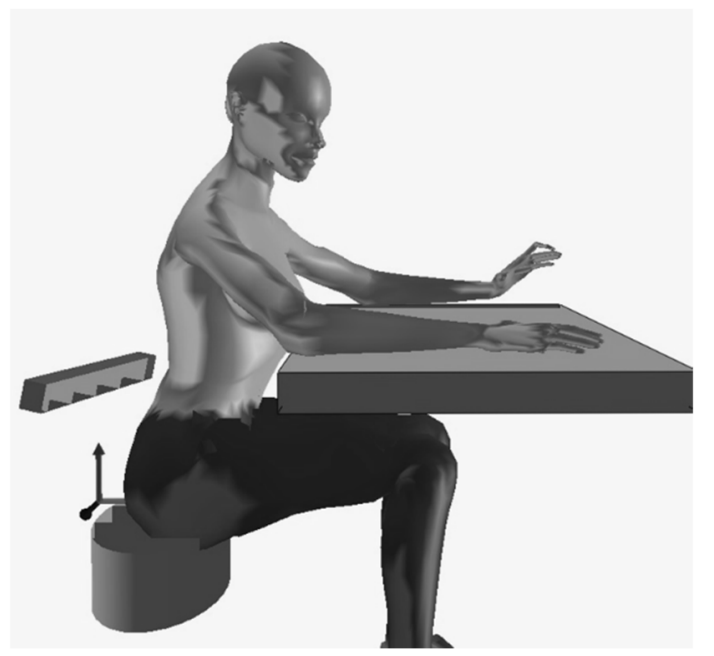

Fig. 3. Incorrect position of hands when working on a moved away keyboard

Employees in most cases used the necessity of removing the keyboard and in the created space they collected paper documentation that was processed or rewritten by them. Fig. 3 presents the observed situation when an employee uses the documentation gathered on the desk (in front of the keyboard), enter the data taken from it to the tables in the computer. Due to the location: keyboard (in front of the employee close to the monitor), monitor (right at an angle in relation to the axis of the position, at eye level), documentation (in front of the keyboard), the employee must: expand the arms to operate the keyboard and mouse efficiently 
(support in the elbows), raise the hand above the keyboard (without support in the wrist overloading the joint), swing the right hand in the wrist to the right to observe the monitor by manipulating the mouse. Observation of the monitor forces the head to move from the documentation to the right of the monitor with possible corrective observation on the keyboard.

\subsection{Incorrect position of the monitor.}

Another problem observed was the incorrect position of the monitor towards the employee. In 23 cases (58\%), the monitor was too low and forced the entire body to be tilted or only to tilt the head. In 19 cases (43\%) the monitor was too far away, which also resulted in the need to incline the whole body forward and prevented comfortable back support by the backrest of the chair. In 17 cases (39\%) the monitor was placed at an angle $\left(10^{\circ}-45^{\circ}\right)$ to the axis of the workplace.

\subsection{Incorrect position of the computer mouse.}

This problem was observed in 4 cases. It resulted mainly from the wrong location of the computer and the lack of order in its wiring. In all observed cases, because of the above reasons, the mouse cable was too short which forced the mouse to be positioned at the edge of the table. As a result, the hand that operated the mouse was unsupported, while the employee was rotated in the torso (rotation angle in the spine about $22^{\circ}$ ) and tilted (forward incline from the vertical by about $11^{\circ}$ ).

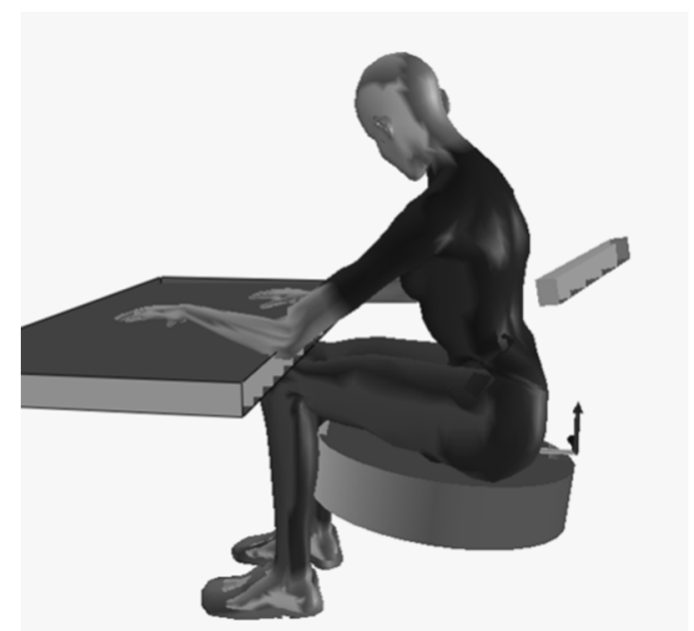

Fig. 4. Incorrect hand position when working with a too short wire of a computer mouse

\section{CONCLUSION}

The conducted research allowed to gain knowledge about working conditions and ergonomic awareness of office workers working at computer stands. The conducted in-depth interview showed that awareness in this respect is small. Employees do not identify their positions at work as improper, moreover, they often think that they are optimal. At the same time, they point to the emerging health disadvantages that they identify as resulting from work. Employees do not see the connection between the incorrect position of the arm and forearm when operating the excessively removed keyboard and the emerging pain in the shoulder joint. Interestingly, the awareness of irregularities in the field of workplace ergonomics decreases as the employee's seniority increases. This may be due to the habituation to abnormal working conditions, some kind of routine, or internal conviction that some health inconvenience must occur at a certain age.

As a result of the diagnosis, prophylactic measures were defined for individual work stations. The most common recommendations were: 
- Use the monitor stand to lift the top edge to eye level.

- Move the monitor towards the worker to the recommended distance of 50-70 cm and ensure that it is positioned in front of the employee.

- Provide a chair with a higher backrest and armrests to adjust their height.

- Raise the seat cushion to a higher height.

- Raise the armrests to the level of the table top.

- Equip the stand with a foot support.

\section{ACKNOWLEDGEMENTS}

The paper is the result of statutory research carried out at the Institute of Production Engineering at the Faculty of Organization and Management of the Silesian University of Technology as part of a project number 13/030/BK_18/0039 called "Development of intelligent production methods as well as work and life environments in the context of production engineering challenges".

\section{REFERENCES}

3D Static Strength Prediction Program ${ }^{\mathrm{TM}}$ Version 7.0.4. [online] Available at: https://c4e.engin.umich.edu/tools-services/3dsspp-software/ [Accessed 15 May 2018].

Bartnicka, J. (2015). Knowledge-based ergonomic assessment of working conditions in surgical ward a case study. Saf. Sci. 2015 vol. 71 pt. B, s. 178-188,

Bartnicka,J., Piedrabuena, A., Portilla, R., Mleczko, K., Moyano-Cuevas, J. L., Pagador, J. B., SanchezMargallo, F. M., Peter, A. and Tokarczyk, J. (2017). Ergonomics education in orthopedic surgery. LIFE: International Journal of Health and Life-Sciences. Vol. 3 iss. 2, s. 194-215.

Bartnicka,J., Piedrabuena, A., Portilla, R., Moyano-Cuevas, J. L., Pagador, J. B., Sanchez-Margallo, F. M., Augut, P., Michalak, D. and Tokarczyk, J. (2018). Train4OrthoMIS online course as a manner of improving ergonomics in orthopaedic surgery. In: Advances in human factors and ergonomics in healthcare and medical devices. Proceedings of the AHFE 2017 International Conferences on Human Factors and Ergonomics in Healthcare and Medical Devices, July 17-21, 2017, Los Angeles, California, USA. V. Duffy, N. Lightner. Eds. Berlin: Springer, 2018, pp. 149158 ,

Burger, G. C. E. and Boer, K. (1968): CET II Ergonomic Task Analysis. Amsterdam.

Kamińska, J. and Tokarski, T. (2016). Jak zorganizować ergonomiczne stanowisko z komputerem? Tablet, laptop, stanowisko z jednym i wieloma monitorami. [online] CIOP-PIB. Available at: https://www.ciop.pl/CIOPPortalWAR/file/83377/2-Z-25-Ergonomiczne-stanowisko-pracy-zkomputerem-J_Kaminska.pdf [Accessed 20 Apr. 2018].

Koszembar-Wiklik, M., Kucerka, D. and Hrmo, R. (2015). Ergonomics of integrated didactic workplaces. Applied natural sciences 2015. 5th International Scientific Conference, Jasna, Low Tatras, September 30 - October 2, 2015. Ed. P. Nemecek. Trnava : Faculty of Natural Sciences University of SS. Cyril and Methodius, 2015, s. 174-180

Mleczko, K. (2016). Wymiana wiedzy, jako czynnik wspomagający proces projektowania ergonomicznych narzędzi medycznych. Systemy Wspomagania w Inżynierii Produkcji z.2, s. 240-248.

PTErg. (1983). Statut Polskiego Towarzystwa Ergonomicznego. (Rozdz. II §11)

Winnicka-Jasłowska, D., Jastrzębska, M. and Tymkiewicz, J. (2017). Ergonomics of laboratory rooms case studies based on the geotechnical laboratories at the Silesian University of Technology. ACEE Archit. Civ. Eng. Environ. 2017 vol. 10 nr 2, pp. 35-41, 